\title{
Preclinical and Early Clinical Development of PTC596, a Novel Small-Molecule Tubulin-Binding Agent
}

Finith Jernigan', Arthur Branstrom', John D. Baird', Liangxian Cao', Mandar Dali', Bansri Furia', Min Jung Kim?', Kylie O'Keefe', Ronald Kong', Oscar L. Laskin', Joseph M. Colacino', Mark Pykett', Anna Mollin', Josephine Sheedy ${ }^{1}$, Melissa Dumble', Young-Choon Moon', Richard Sheridan', Tobias Mühlethaler ${ }^{3}$, Robert J. Spiegel', Andrea E. Prota ${ }^{4}$, Michel O. Steinmetz ${ }^{3,4}$, and Marla Weetall ${ }^{1}$

\section{ABSTRACT}

PTC596 is an investigational small-molecule tubulin-binding agent. Unlike other tubulin-binding agents, PTC596 is orally bioavailable and is not a P-glycoprotein substrate. So as to characterize PTC596 to position the molecule for optimal clinical development, the interactions of PTC596 with tubulin using crystallography, its spectrum of preclinical in vitro anticancer activity, and its pharmacokinetic-pharmacodynamic relationship were investigated for efficacy in multiple preclinical mouse models of leiomyosarcomas and glioblastoma. Using X-ray crystallography, it was determined that PTC596 binds to the colchicine site of tubulin with unique key interactions. PTC596 exhibited broad-spectrum anticancer activity.

\section{Introduction}

PTC596 is an investigational small-molecule tubulin-binding agent currently in clinical development. PTC596 has high oral bioavailability, is not a $\mathrm{P}$-glycoprotein $(\mathrm{P}-\mathrm{gP})$ substrate, and readily crosses the blood-brain barrier (BBB). Microtubules are dynamic filaments composed of $\alpha \beta$-tubulin heterodimers. They act as scaffolds to determine cell shape and play a central role in cell motility, transportation of organelles within the cytoplasm, and the organization and movement of chromosomes during mitosis and meiosis. Modulating microtubule dynamics can drastically alter a cell's viability by arresting the cell cycle, inhibiting cell migration, or initiating programmed cell death or apoptosis. A wide variety of tubulin-binding agents modulate their assembly properties. Currently, there are six distinct tubulin sites to which various ligands are known to interact (reviewed in (1); (2-4)). The classes of compounds targeting the sites include taxanes, vinca alkaloids, laulimalide/peloruside, pironetin, maytansine and colchicine. Tubulin-binding agents have been used clinically for years and rep-

'PTC Therapeutics, Inc., South Plainfield, New Jersey. ${ }^{2}$ InSeption Group, Lansdale, Pennsylvania. ${ }^{3}$ University of Basel, Biozentrum, Basel, Switzerland. ${ }^{4}$ Laboratory of Biomolecular Research, Division of Biology and Chemistry, Paul Scherrer Institut, Villigen PSI, Switzerland.

Note: Supplementary data for this article are available at Molecular Cancer Therapeutics Online (http://mct.aacrjournals.org/).

Corresponding Author: Marla Weetall, PTC Therapeutics, Inc. 100 Corporate Court, South Plainfield, NJ 07080. E-mail: mweetall@ptcbio.com

Mol Cancer Ther 2021;20:1846-57

doi: 10.1158/1535-7163.MCT-20-0774

This open access article is distributed under Creative Commons AttributionNonCommercial-NoDerivatives License 4.0 International (CC BY-NC-ND).

(C)2021 The Authors; Published by the American Association for Cancer Research
PTC596 showed efficacy as monotherapy and additive or synergistic efficacy in combinations in mouse models of leiomyosarcomas and glioblastoma. PTC596 demonstrated efficacy in an orthotopic model of glioblastoma under conditions where temozolomide was inactive. In a first-in-human phase I clinical trial in patients with cancer, PTC596 monotherapy drug exposures were compared with those predicted to be efficacious based on mouse models. PTC596 is currently being tested in combination with dacarbazine in a clinical trial in adults with leiomyosarcoma and in combination with radiation in a clinical trial in children with diffuse intrinsic pontine glioma. resent one of the most successful classes of anticancer drugs (5). While several drugs that bind to the taxane, vinca, and maytansine sites have been approved for cancer indications by the FDA, either as free drugs or as antibody-drug conjugates, currently there are no drugs targeting the laulimalide/peloruside, pironetin or colchicine sites approved for use in cancer.

The clinical efficacy of the taxanes and vinca alkaloids is often diminished by the membrane-associated ATP-binding cassette transporter mediated P-gp drug efflux pump, a product of the multidrug resistance gene $(A B C B 1$; ref. 6$)$ that is expressed in a variety of tissues including intestine, liver, kidney, and in the capillary endothelial cells that form the BBB (7). Overexpression of P-gp in many tumor cell lines decreases intracellular drug concentrations, subsequently limiting effective drug cytotoxicity. Cancer cells may develop resistance to standard-of-care (SOC) chemotherapeutics by upregulating P-gp $(8,9)$.

Taxanes and vinca alkaloids also exhibit low oral bioavailability and therefore are administered IV. This is due in part to poor aqueoussolubility, high molecular weight, an affinity for the P-gp drug efflux pump in the gut, and vulnerability to first pass hepatic elimination, primarily by cytochrome P450 CYP3A4 (10-12). As substrates for P-gp, they do not cross the BBB, resulting in limited use in central nervous system (CNS) indications. In addition, clinical use of taxanes and vinka alkaloids is often limited by a sometimes irreversible, chronic peripheral sensory neuropathy, likely due to axonal degradation (13-15). Approval of nanoparticle albuminbound (nab) paclitaxel reduced the adverse effect profile of paclitaxel but nab-paclitaxel does not differ from solvent-based paclitaxel in terms of neurotoxicity (16).

PTC596 is an investigational orally bioavailable small molecule that targets a broad range of cancer types. PTC596 was originally identified by its ability to inhibit proliferation of cancer stem cells expressing B-cell-specific Moloney murine leukemia virus insertion site 1 (BMI1) protein $(17,18)$. More recent work has demonstrated that the downregulation of BMI1 protein levels and function is a 
secondary event due to potent induction of $\mathrm{G}_{2}-\mathrm{M}$ mitotic arrest and apoptosis induced by inhibition of tubulin polymerization by PTC596 (19). In contrast to many tubulin-binding agents, PTC596 is not a substrate for P-gp as demonstrated by its ability to kill cancer cells over-expressing P-gp and crosses the BBB (19), making it an attractive candidate for many oncological indications, including neuro-oncology. PTC596 also has compelling pharmacologic properties, including the ability to be administered orally in vivo as a simple suspension formulation, a long circulating half-life, and effective biodistribution into tumors in mice (19). PTC596 has been shown to enhance synergistically the activity of gemcitabine with nab-paclitaxel in a mouse model of pancreatic cancer (19). Here, we extend our earlier findings to characterize the properties and mechanism of action of PTC596 and in the context of data from a phase I first-in-human study, positioning the molecule for optimal clinical testing in solid tumors.

\section{Materials and Methods}

Additional details are presented in Supplemental Materials for all experiments.

\section{Crystallography}

The complex of two $\alpha \beta$-tubulin heterodimers, one stathmin-like domain of RB3 (RB3-SLD), and one tubulin tyrosine ligase (TTL) (the $\mathrm{T}_{2} \mathrm{R}$-TTL complex) was produced as described $(20,21)$. Single-crystal monochromatic diffraction data were recorded at the X06DA beamline of the Swiss Light Source (Paul Scherrer Institut, Villigen PSI, Switzerland). Data were processed and merged with XDS (22) to $2.05 \AA$ resolution.

\section{Cell screening using cell viability inhibition assays}

CellTiter-Glo Luminescent Cell Viability Assays were performed by Crown Bioscience Inc. using a panel of 239 cell lines and in-house using a panel of 33 cell lines that included a range of tumor types. Tumor cells were treated with increasing concentrations of PTC596 or other SOC drugs and were assessed for viability after 72 hours. The concentration resulting in $50 \%$ reduction in cell viability $\left(\mathrm{CC}_{50}\right)$ value was determined from a non-linear regression curve using Prism version 8.4.3 (Graphpad Software).

\section{Orthotopic and subcutaneous xenograft studies \\ Tumor and cell lines}

HT1080 cells (a human fibrosarcoma cell line), U-87 MG cells (a human glioblastoma cell line), and SK-UT-1 and SK-LMS-1 cells (human LMS cell lines) were obtained from the ATCC and cultured using methods provided by the ATCC. Prior to implantation, the SKLMS- 1 cells were serial passaged seven cycles in male athymic nude mice to generate a more aggressive tumor model. The D-09-0500 MG xenograft line has been previously described (23) and was generated from a treatment-naïve 58-year-old male glioblastoma (GBM) patient undergoing surgery at Duke University Medical Center (Durham, NC) and was maintained by serial subcutaneous passage in athymic nude mice.

\section{In vivo implantation and tumor growth}

All in vivo studies were performed at an Association for Assessment and Accreditation of Laboratory Animal Care International (AAALAC)-certified facility under Institutional Animal Care and Use Committee (IACUC)-approved protocols. The day treatment initiated was denoted as day 0 . An animal was taken off study when it attained endpoint (e.g., death, moribundity, or tumor volume endpoint) or if it exhibited a body weight loss $\geq 20 \%$ of its initial day 0 body weight. For dose optimization studies, HT1080 fibrosarcoma or U-87 MG GBM tumor cells $\left(5 \times 10^{6}\right.$ cells in $0.2 \mathrm{~mL} 50 \%$ Matrigel $)$ were inoculated subcutaneously into the right flank of athymic nude mice. For the orthotopic GBM study, athymic nude mice were injected intracranially with U-87 MG tumor cells $\left(2 \times 10^{5}\right.$ in $2 \mu \mathrm{L}$ PBS $)$ at the right frontal lobe, $2 \mathrm{~mm}$ lateral and $0.5 \mathrm{~mm}$ anterior from bregma at a depth of $3.5 \mathrm{~mm}$. For the patient-derived GBM xenograft study, D-09-0500 MG tumors were removed from host animals under sterile conditions, homogenized into a cell suspension, and injected subcutaneously $(50 \mu \mathrm{L})$ into the right flank of athymic nude mice.

For subcutaneous xenograft studies, tumors were measured using digital calipers. Tumor volumes were calculated as $\left(l x w^{2}\right) / 2$, where $l$ was the longest tumor measurement and $w$ was the shortest tumor measurement. When tumors reached the appropriate size, mice were randomized into groups so that the average initial tumor size was the same across groups within a study.

\section{Analyses for xenograft studies}

For subcutaneous xenograft studies, mice were taken off study when individual tumor volumes were $\geq 1,000 \mathrm{~mm}^{3}$, mice were moribund or found dead, or on the final day of the study, whatever came first. The time for the tumor in an individual mouse to reach $1,000 \mathrm{~mm}^{3}$ was calculated using the FORECAST function in Excel and then the median time across the group determined. Differences in the distribution of time-to-endpoint (time to $1000 \mathrm{~mm}^{3}$ or death in days) were analyzed by the Kaplan-Meier method and the log-rank test. Mean tumor growth curves were plotted and truncated when $50 \%$ of test animals were taken off study. For the orthotopic GBM survival study, the MST was determined for each treatment group and the increase in lifespan, expressed as a percentage of the control, was calculated. Graphical presentations and statistical analyses were performed using GraphPad Prism version 8.4.3 for Windows, (GraphPad Software).

\section{Synergy scores}

The interaction between PTC596 and the various compounds was evaluated using the fractional product method (24). The expected effect of PTC596 and a compound acting independently was calculated as the product of the unaffected fractions after treatment with either drug alone. Then, the potential interaction of the combined drugs was determined by calculating a Synergy Score as the ratio of observed to expected, where Synergy Score $<0.7$ indicated synergy.

\section{Phase I clinical trial}

A phase I first-in-human study was performed in solid tumor patients. Written informed consent was obtained from the patients and the studies were conducted in accordance with the Declaration of Helsinki, Council for International Organizations of Medical Sciences (CIOMS), Belmont Report, and the U.S. Common Rule. The study was approved by all participating institutional review boards. The starting dose was $0.65 \mathrm{mg} / \mathrm{kg}$ twice weekly, calculated as one-tenth of the human equivalent dose (HED) of $40 \mathrm{mg} / \mathrm{kg}$ twice weekly, the severely toxic dose in $10 \%$ of rats (STD 10) as per FDA guidelines (25). Doses were increased, based on tolerability, according to the protocolspecified variation on the " $3+3$ " dose escalation scheme to a maximum dose of $10 \mathrm{mg} / \mathrm{kg}$ (26). Tumor response was evaluated every other treatment cycle according to RECIST or RANO criteria. Additional details are in the Supplementary data. 


\section{Results}

\section{PTC596 is a structurally novel tubulin-binding agent}

PTC596 is an amine substituted reverse pyrimidine described chemically as 5 -fluoro-2-(6-fluoro-2-methyl- $1 H$-benzo[ $d]$ imidazole1 -yl)- $N_{4^{-}}$(4-(trifluoromethyl)phenyl)pyrimidine-4,6-diamine. The PTC596 chemical structure is shown in Fig. 1A. That of colchicine is shown in Fig. 1B. Structures for two PTC596 analogues are shown in Fig. 1C.

\section{PTC596 targets the colchicine site of tubulin}

Competition studies demonstrated that PTC596 is competitive with colchicine but not with vinblastine (Supplementary Fig. S1).
Many tubulin-binding agents that target the colchicine site bear the trimethoxyphenyl moiety that is essential to their interaction with tubulin (4). As an amine substituted pyrimidine compound that lacks the trimethoxyphenyl moiety, PTC596 is structurally distinct from other tubulin-binding agents that target the colchicine site.

To confirm this, the specific binding site was identified using X-ray crystallography. The cocrystal structure of PTC596 bound to a complex composed of two $\alpha \beta$-tubulin heterodimers, one stathmin-like domain of RB3 (RB3-SLD), and one tubulin tyrosine ligase (TTL; the $\mathrm{T}_{2} \mathrm{R}-\mathrm{TTL}$ complex) was determined (Fig. 1D, right). As shown in Fig. 1D, PTC596 occupies the colchicine site located at the interface of the tubulin monomers of the heterodimer and directly adjacent to

\section{A PTC596}<smiles>COc1ccc2c(c1)[C@H](NC(C)=O)CCc1cc(OC)c(OC)c(OC)c1-2</smiles>

C PTC596 analogues<smiles>Cc1nc2ccccc2n1-c1cc(NNc2ccc(C(F)(F)F)cc2)nc(N)n1</smiles><smiles>CCc1nc2ccc(P)cc2n1-c1cc(NN)nc(Nc2ccc(C(F)(F)F)cc2)n1</smiles>

D PTC596 relative position to tubulin

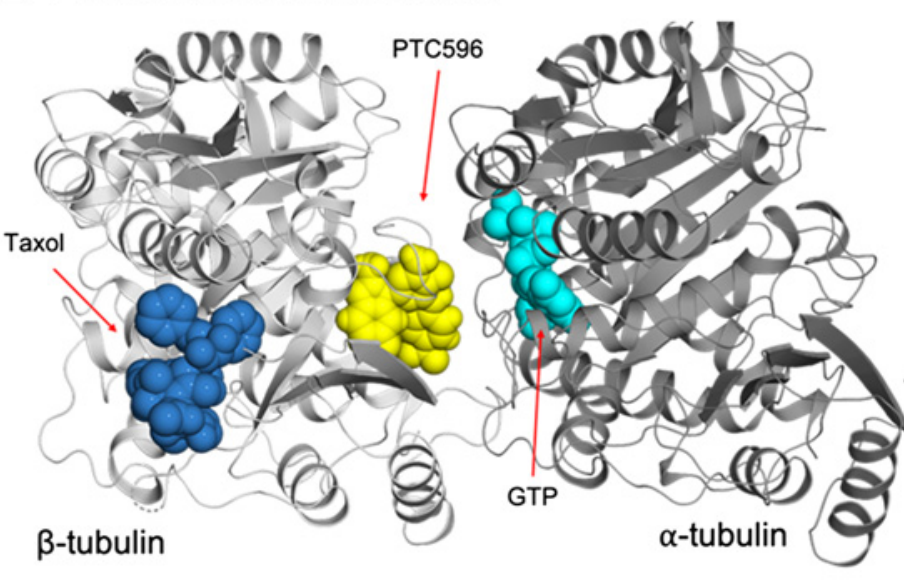

E PTC596 in the colchicine binding pocket

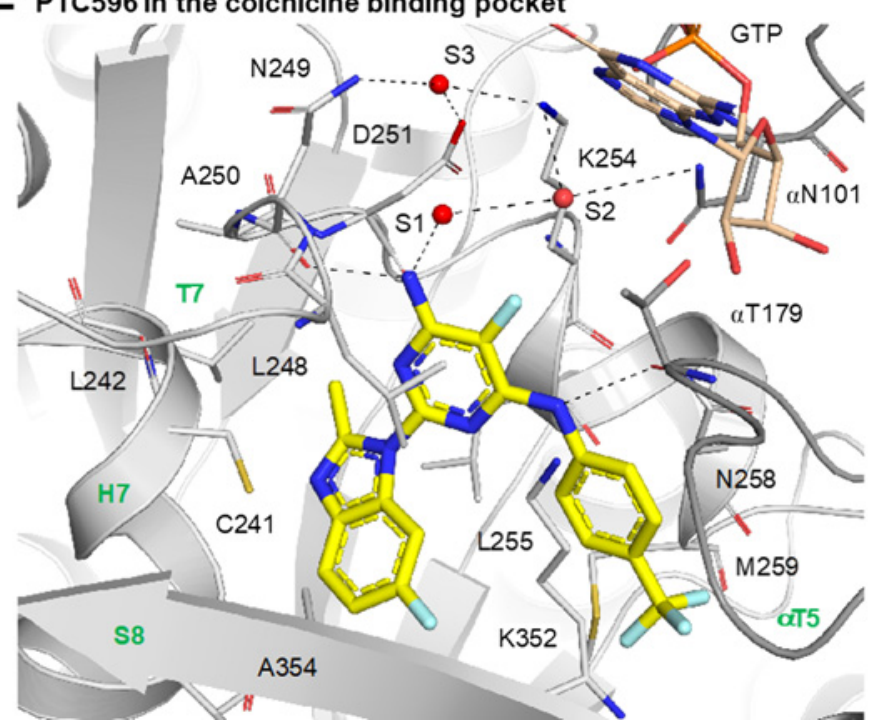

Figure 1.

PTC596 and colchicine chemical structures and X-ray analysis of the $\mathrm{T}_{2}$ R-TTL-PTC596 complex. A, PTC596: 5-fluoro-2-(6-fluoro-2-methyl-1H-benzo[d]imidazole-1yl)- $N_{4}$-(4-(trifluoromethyl)phenyl) pyrimidine-4,6-diamine. B, Colchicine: $N$-[(7S)-1,2,3,10-Tetramethoxy-9-oxo-5,6,7,9-tetrahydrobenzo [a]heptalen-7yl]acetamide. C, Two PTC596 analogues: PTC-646 and PTC-867. D, Overall view of the tubulin-PTC596 complex structure. PTC596 (yellow spheres) binds at the interface between $\alpha$-tubulin (dark gray ribbon) and $\beta$-tubulin (light gray ribbon) in close proximity to the GTP (cyan spheres)-binding site. The superimposed structure of taxol bound to the taxane site in $\beta$-tubulin (dark blue; PDB: 1JFF, RMSD: $1.609 \AA$ ) is shown for comparison. E, Close-up view of PTC596 (yellow/blue sticks) and the surrounding binding pocket formed by $\alpha$ - and $\beta$-tubulin. Interacting residues of tubulin are shown in stick representation and are labeled. Oxygen and nitrogen atoms are colored red and blue, respectively. Hydrogen bonds are depicted as black dashed lines. Secondary structural elements of tubulin are labeled in green. For simplicity, only $\alpha$-tubulin residues are indicated with an $\alpha$. Oxygen atoms of water molecules in proximity of the ligand are represented as red spheres. 
the GTP-binding site of $\alpha$-tubulin. The overall structure of the $T_{2} \mathrm{R}$ TTL-PTC596 complex (all chains) superimposed well with the one from the apo $\mathrm{T}_{2} \mathrm{R}$-TTL structure (PDB: $4 \mathrm{I} 55$, RMSD: $0.42 \AA$ over $1964 \mathrm{C}_{\alpha}$-atoms). This suggests that upon binding, PTC596 does not affect the overall conformation of tubulin except for a difference in the orientation of the T7-loop residues of $\beta$-tubulin in the holoversus apo-state.

As shown in Fig. 1E, PTC596 binds to the colchicine site of tubulin, which is formed by residues of strands S8, S9 and S10, loop T7, helices H7 and H8 of $\beta$-tubulin, and loop T5 of $\alpha$-tubulin. The central 5 -fluoro-pyrimidine-4,6-diamine moiety is packed between the side chain of $\beta$ Leu248 and the main chain C $\alpha$ of $\beta$ Leu255. The 4- and 6 -amino groups form two hydrogen bonds to both the main chain carbonyls of $\beta$ Ala 250 and $\alpha$ Thr 179 , respectively. The 4 -amino group is in water-mediated contact to both the side chains of $\beta$ Lys 254 and $\alpha$ Asn101 facing the nucleotide at the N-site. The 4-(trifluoromethyl) phenyl moiety is buried into a pocket shaped by the hydrophobic side chains of $\beta$ Met $259, \beta$ Thr314, $\beta$ Ala316, $\beta$ Lys352, and $\alpha$ Val181. Moreover, the phenyl-ring is stacked between the side chains of $\beta$ Asn 258 and $\beta$ Lys352. The interaction is completed by the 6-fluoro-2-methyl$1 H$-benzo[d]imidazole-1-yl moiety, which inserts into the pocket formed by the side chains of $\beta$ Val238, $\beta$ Cys241, $\beta$ Leu242, $\beta$ Leu255, $\beta$ Met259, $\beta$ Ala316, $\beta$ Ile318, and the hydrophobic moiety of the $\beta$ Lys352 side chain. The 2-methyl group of the benzimidazolyl moiety is facing the T7 loop of $\beta$-tubulin.

As shown in Supplementary Fig. S2, to compare the binding mode of PTC596 with that of colchicine, the $\beta$-tubulin chains of the respective tubulin-ligand complexes were superimposed. The major difference between PTC596 and colchicine in occupied space in the binding site is caused by the absence of the colchicine acetamidegroup, which results in a flip of both the $\alpha \mathrm{T} 5$ - and the $\beta \mathrm{T} 7$ - loops and on the side chain orientation of $\beta$ Lys352. In the PTC596 structure, a water molecule is present in the space taken by the $\beta$ Lys352 sidechain in the colchicine structure.

In addition to the co-crystal structure of PTC596 in complex with tubulin, autodocking studies were performed with the closely related PTC596 analogs, PTC-867, PTC-646, P295339, and P296233 [Supplementary Fig. S2C-S2F)]. PTC-295339, and P296233 also down-regulate BMI-1 protein (Supplementary Fig. S3). Predicted binding sites for PTC-867 and PTC-646 overlapped very well with the PTC596 binding mode from the crystal structure. These results suggest that both related analogs can adopt a similar binding mode to PTC596. However, P295339 and P296233 adopted different binding modes than PTC596, likely due to the lack of a 4-amino substitution, rendering them unable to participate in a key hydrogen bonding interaction with BAla250. These results suggest P-295339 and P296233 do not bind tubulin and could function to downregulate the BMI1 protein via a different mechanism.

\section{PTC596 exhibits broad-spectrum antiproliferative activity}

Two series of cell screens were carried out to assess the effect of PTC596 on the proliferation of cancer cell lines as well as to elucidate its potential mechanism of action. The first set of studies was designed to evaluate the spectrum of PTC596 activity across different tumor
Figure 2.

Cell screening. A, Cell lines were defined as sensitive or resistant cell lines for $\mathrm{CC}_{50}$ values $\leq 1.2 \mu \mathrm{mol} / \mathrm{L}$ and $>1.2 \mu \mathrm{mol} / \mathrm{L}$, respectively. For each cancer type the median of the responders indicated by a horizontal line and the percent responders by $(n \%)$ in the legend. B, Thirty-three cell lines representing twelve cancer types and normal fibroblasts were tested for sensitivity to PTC596 and to eleven other compounds including analogs of PTC596 (PTC-646 and PTC-867), other known tubulin-binding agents (Taxol and indibulin), PTC299 (42) and PTC-868, both inhibitors of dihydroorotate dehydrogenase (DHODH, an enzyme involved in de novo pyrimidine nucleotide synthesis), compounds that inhibit BMI-1 and with similar activity as PTC209, inhibitors of BMII mRNA translation (P296233 and P295339), and other known cytotoxic agents (puromycin, sunitinib, and doxorubicin). Individual $\mathrm{CC}_{50}$ values for each compound were calculated for each cell line (Supplementary Table $\mathrm{S1}$ ) and the $\mathrm{CC}_{50}$ means were compared to that of PTC596 by evaluating the Pearson correlation coefficient ( $r$ statistic), the coefficient of determination $\left(R^{2}\right)$, and the $P$ value (as a measure of the $r$ statistic deviation from zero). The mean $\mathrm{CC}_{50}$ value for PTC596 was most similar to those of chemical analogues and other tubulin-binding agents as demonstrated by the high $R$-squared $\left(R^{2}\right)$ and Pearson $r$ statistic color coded from high to low as blue to orange, respectively. Abbreviations: BMII, BMII gene expression; $\mathrm{CC}_{50}$, concentration resulting in a $50 \%$ decrease in cell viability; DHODH, dihydroorotate dehydrogenase; MDA, microtubule destabilizing agent; MOA, mechanism-of-action; MSA, microtubule stabilizing agent; protein syn, protein synthesis: TK, tyrosine kinase; topo II, topoisomerase II.

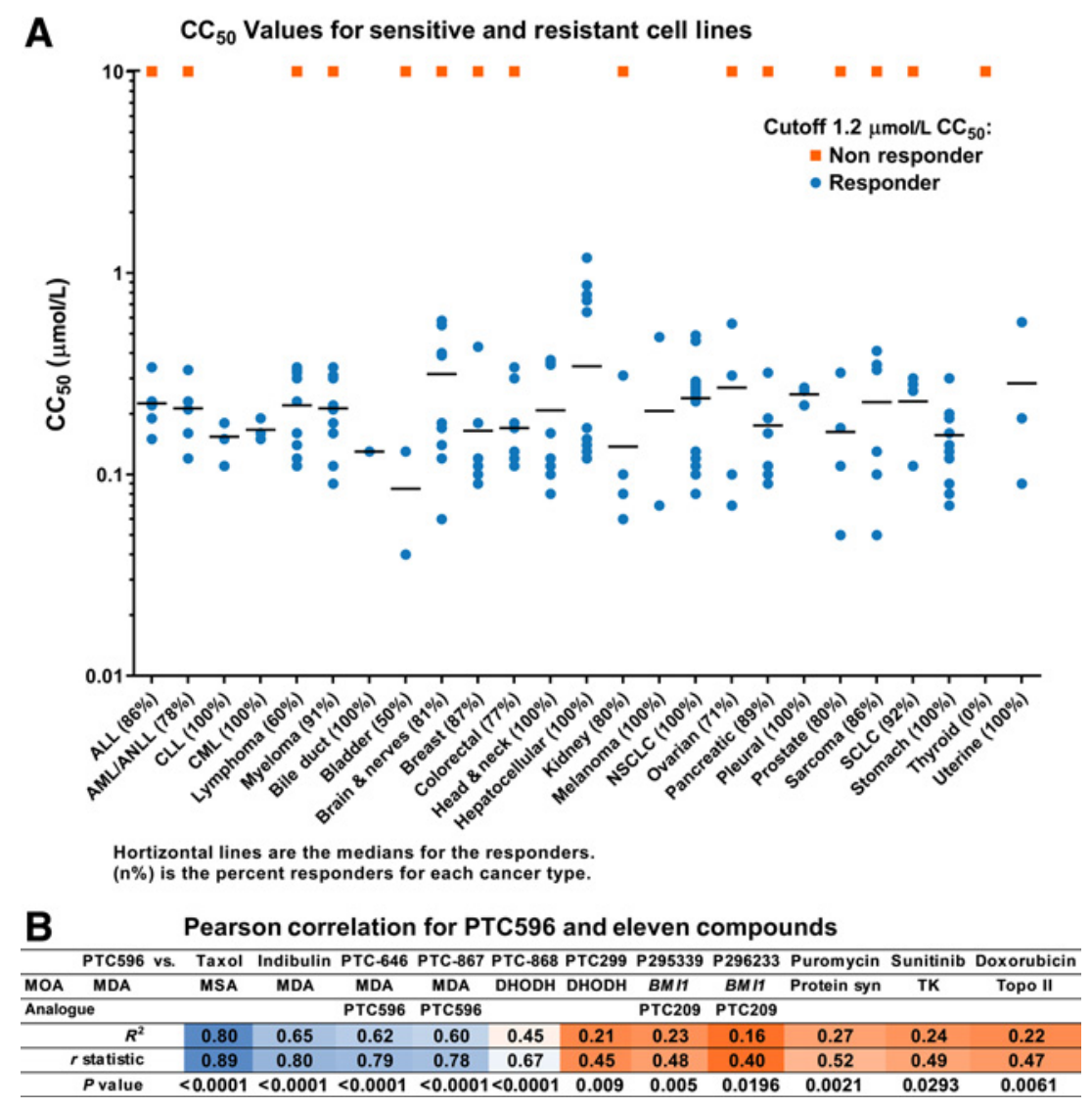


types. In this study, 239 cancer cell lines that included a range of tumor types were tested for sensitivity to PTC596. As shown in Fig. 2A, PTC596 exhibited broad-spectrum activity inhibiting 208 or $87 \%$ of the cell lines tested [concentration resulting in a $50 \%$ decrease in cell viability $\left(\mathrm{CC}_{50}\right)$ at $\left.\leq 1.2 \mu \mathrm{mol} / \mathrm{L}\right]$. The least responsive cancer cell lines with $\leq 60 \%$ sensitivity were lymphoma, bladder, and thyroid (See Supplementary File S2).

The second series of studies was designed to determine whether the pattern of sensitivity across multiple cell lines would give insight into the mechanism of action. In these studies, 33 cell lines as summarized in Supplementary Table S1 representing 12 cancer types and normal fibroblasts were tested for sensitivity to PTC596 and to 11 other compounds. These compounds included drugs that act by different mechanisms including other analogs of PTC596, other tubulinbinding agents, inhibitors of the enzyme dihydroorotate dehydrogenase (DHODH, involved in biosynthesis of pyrimidine nucleotides), and known cytotoxic agents. As shown in Fig. 2B, the $\mathrm{CC}_{50}$ values for PTC596 were most similar to those of 2 chemical analogues as well as to other tubulin-binding agents as demonstrated by the high R-squared $\left(R^{2}\right)$ and Pearson $r$ statistic.

\section{PTC596 efficacy correlates with $C_{\max }$ in dose optimization studies}

Preclinical studies were conducted to optimize the dose and regimen of PTC596 (Fig. 3). In the HT1080 model of fibrosarcoma, PTC596 was not active when orally administered once daily at $5 \mathrm{mg} / \mathrm{kg}$ (a weekly dose of $35 \mathrm{mg} / \mathrm{kg}$ ). However, PTC596 was active when administered at $10 \mathrm{mg} / \mathrm{kg}$ twice per week (a weekly dose of $20 \mathrm{mg} / \mathrm{kg}$ ) or every other day (a weekly dose of $\sim 35 \mathrm{mg} / \mathrm{kg}$ ). In the U-87 MG model of GBM, similar responses were seen with $10 \mathrm{mg} / \mathrm{kg}$ PTC596 dosed twice per week, every other day, or 3 times per week (data not shown). These data are consistent with efficacy related to the $C_{\max }$, rather than efficacy correlating with the AUC or time above a threshold.

A dosing regimen of 12 or $12.5 \mathrm{mg} / \mathrm{kg}$, orally, twice per week was subsequently utilized for combination studies. A dose of $20 \mathrm{mg} / \mathrm{kg}$ once-per-week was more effective, but a suboptimal dose of $12.5 \mathrm{mg} / \mathrm{kg}$ twice per week was used for combination studies allowing for easier detection of a synergistic response. The twice weekly dosing schedule was selected on the basis of the similar responses to twice per week as every other day ( 3 or 4 times per week), which indicated little improvement in response with more frequent dosing (Fig. 3A).

A Summary of responses for dose optimization studies

\begin{tabular}{|c|c|c|c|c|c|c|c|c|c|c|c|}
\hline Group & $\mathbf{N}$ & Treatment & $(\mathrm{mg} / \mathrm{kg}$ & $\begin{array}{l}\text { se } \\
(\mathrm{mL} / \mathrm{kg})\end{array}$ & Route & Schedule & $\begin{array}{c}\text { Total weekly } \\
\text { dose } \\
\text { (total mg/kg) }\end{array}$ & $\begin{array}{l}\% \text { Tumor growth } \\
\text { inhibition } \\
\text { (Day 17) }\end{array}$ & $\begin{array}{l}\text { Median time } \\
\text { to } 1,000 \mathrm{~mm}^{3} \\
\text { (Days) }\end{array}$ & $\begin{array}{l}\text { \% Tumor } \\
\text { growth delay }\end{array}$ & $\begin{array}{c}\text { No. TFS } \\
\text { /No. study survivors } \\
\text { (TFS/SS) }\end{array}$ \\
\hline 1 & 10 & Vehicle & 0 & 10 & $\mathrm{PO}$ & QD & 0 & $0 \%$ & 17.1 & $0 \%$ & $0 / 0$ \\
\hline 2 & 10 & PTC596 & 5 & 10 & $\mathrm{PO}$ & QD & 35 & $38 \%$ & 26.8 & $57 \%$ & $0 / 0$ \\
\hline 3 & 10 & PTC596 & 10 & 10 & PO & QW & 10 & $43 \%$ & 21.3 & $25 \%$ & $0 / 0$ \\
\hline 4 & 10 & PTC596 & 10 & 10 & $\mathrm{PO}$ & BIW & 20 & $93 \%$ & 53.0 & $211 \%$ & $3 / 7$ \\
\hline 5 & 10 & PTC596 & 10 & 10 & $\mathrm{PO}$ & QOD & $40 / 30$ alt wks & $93 \%$ & 53.0 & $211 \%$ & $2 / 6$ \\
\hline
\end{tabular}

B

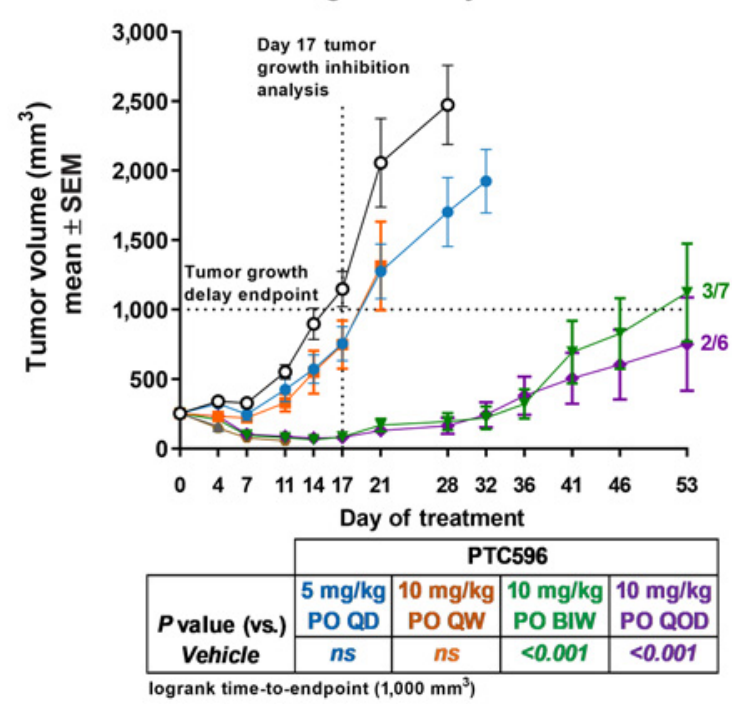

C

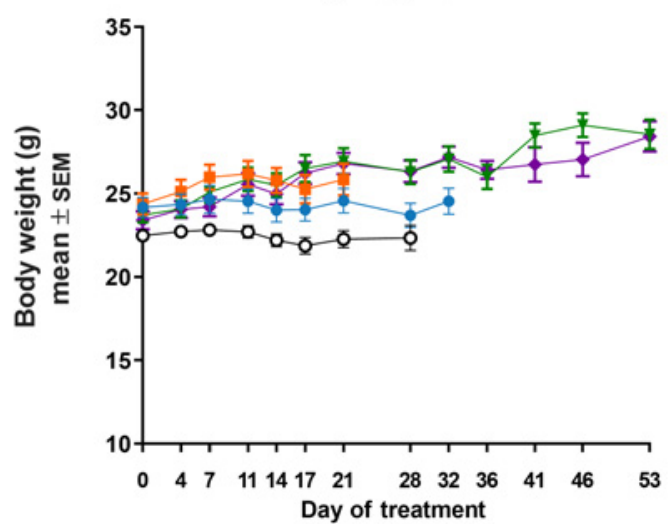

-o- Vehicle, PO, QD

- $5 \mathrm{mg} / \mathrm{kg}, \mathrm{PO}, \mathrm{QD}$
=- $10 \mathrm{mg} / \mathrm{kg}, \mathrm{PO}, \mathrm{QW}$

$\checkmark 10 \mathrm{mg} / \mathrm{kg}, \mathrm{PO}, \mathrm{BIW}$

$\rightarrow 10 \mathrm{mg} / \mathrm{kg}, \mathrm{PO}, \mathrm{QOD}$

Figure 3.

PTC596 dose optimization. A, Percent tumor growth inhibition was determined on day 17, the last day all vehicle control mice remained on study. For each group, the median time for tumor volume to reach $1,000 \mathrm{~mm}^{3}$ in days was calculated. At study end, the number of mice with tumors that were too small to measure was evaluated. B, Symbols represent the mean tumor volumes $\left(\mathrm{mm}^{3}\right) \pm$ the SEMs. The day of tumor growth inhibition (day 17) is shown as a vertical dotted line. The delay in tumor volumes reaching $1,000 \mathrm{~mm}^{3}$ is shown by the horizontal line. As shown in the inset table, the log-rank test was employed to assess the significance of the difference in the distribution of time-to-endpoint (time to $1,000 \mathrm{~mm}^{3}$ or death in days) values for treated groups versus the vehicle group with $P$ values corrected for multiple comparisons. C, Symbols represent the mean body weights $(\mathrm{g}) \pm \mathrm{SEMs}$. Mean tumor growth and body weight curves are truncated on the first day that $\geq 50 \%$ of the animals in a group attained the endpoint tumor volume. Abbreviations: alt wks, alternate weeks; NC, not calculated; TFS/SS, the number of animals that survived the study with tumors too small to measure (TFS)/the number of animals remaining at study end (SS). 
This regimen $(12.5 \mathrm{mg} / \mathrm{kg}$ twice per week) was supported by pharmacokinetic studies that showed PTC596 is highly bioavailable in mice when orally administered. The pharmacokinetics of PTC596 was measured in mice at $10 \mathrm{mg} / \mathrm{kg}$ in athymic nude mice. At $10 \mathrm{mg} / \mathrm{kg}$, the $C_{\max }$ is $1,156 \mathrm{ng} / \mathrm{mL}$ and the AUC is 19,252 hour* $\mathrm{ng} / \mathrm{mL}$. Assuming that exposure of PTC596 increases linearly between $10 \mathrm{mg} / \mathrm{kg}$ and $12.5 \mathrm{mg} / \mathrm{kg}$, the estimated $C_{\max }$ associated with $12.5 \mathrm{mg} / \mathrm{kg}$ would be $1,445[1156 \times(12.5 / 10)] \mathrm{ng} / \mathrm{mL}$. Because efficacy in vivo often correlates with the levels of drug that is not bound to protein (i.e., free drug), the free drug in the plasma of mice at $12.5 \mathrm{mg} / \mathrm{kg}$ was also calculated. In the mouse, $99.5 \%$ of the PTC596 is protein bound so that the free drug concentration at the $C_{\max }\left(f C_{\max }\right)$ at $12.5 \mathrm{mg} / \mathrm{kg}$ is estimated to be $7.2 \mathrm{ng} / \mathrm{mL}(27,28)$.

PTC596 is efficacious in preclinical models of leiomyosarcoma

Leiomyosarcoma is one of the most common subtypes of soft tissue sarcomas, comprising $10 \%$ to $28 \%$ of all soft tissue sarcomas (29-36). Typically, leiomyosarcoma has a complex karyotype and is associated with p53 deficiency, the most commonly reported genetic mutation in leiomyosarcoma $(37,38)$. The uterine and vulvar leiomyosarcoma cell lines, SK-UT-1 and SK-LMS-1, used in this study express this characteristic leiomyosarcoma phenotype.

In the 145-day study shown in Fig. 4A and B, PTC596 delayed growth of SK-UT-1 leiomyosarcoma tumor cells in vivo alone and in combination with Taxotere (docetaxel). The figures show the mean tumor volumes with time and Supplementary Table S2 summarizes the data for each treatment regimen. The median time for tumors to reach $1,000 \mathrm{~mm}^{3}$ in vehicle dosed mice was 18.6 days. In mice dosed with PTC596 monotherapy $[12.5 \mathrm{mg} / \mathrm{kg}$, twice weekly for 6 weeks $(12$ doses), oral], the median time to $1,000 \mathrm{~mm}^{3}$ was significantly delayed over vehicle at 31.2 days ( $68 \%$ increase, $P=0.0306$ by log-rank test). Taxotere monotherapy at $5 \mathrm{mg} / \mathrm{kg}$ [twice weekly for 5 and $1 / 2$ weeks (11 doses), i.p.] demonstrated little efficacy with a median time to 1,000 $\mathrm{mm}^{3}$ of 19.3 days ( $4 \%$ increase). Taxotere monotherapy at $15 \mathrm{mg} / \mathrm{kg}$ (QW6, once per week for 6 weeks i.p., 6 doses) was more effective than PTC596 or the lower dose of Taxotere, significantly prolonging the median time to $1,000 \mathrm{~mm}^{3}$ to 48.7 days ( $163 \%$ increase, $P<0.0010$ by log-rank test). The corresponding combination therapies were significantly more efficacious than any of the monotherapies, with a median time to $1,000 \mathrm{~mm}^{3}$ of 78.6 days ( $324 \%$ increase, $P<0.0010$ by log-rank test) at $5 \mathrm{mg} / \mathrm{kg}$ and a median time to $1,000 \mathrm{~mm}^{3}$ of 145 days (682\% increase, $P<0.0010$ by log-rank test) with 8 study survivors of which 8 had no measurable tumor (noted as $8 / 8$ tumor free survivors) at $15 \mathrm{mg} / \mathrm{kg}$ QW6. Both regimens exhibited strong day 25 synergy scores of 0.2 and 0.3 , respectively. The response to Taxotere at $15 \mathrm{mg} / \mathrm{kg}$ with PTC596 was the most efficacious.

The 165-day study shown in Fig. 4C-F and Supplementary Table S3 evaluated the efficacy of PTC596 alone and in combination with Doxil (doxorubicin liposomal) at 3 or $9 \mathrm{mg} / \mathrm{kg}$ or DTIC (dacarbazine) at 4 or $21 \mathrm{mg} / \mathrm{kg}$ in the treatment of SK-LMS-1 human leiomyosarcoma xenografts in mice.

The median time for SK-LMS-1 tumors in vehicle-dosed mice to reach $1,000 \mathrm{~mm}^{3}$ was 17.7 days and was 23.0 days (30\% increase) for mice treated with PTC596 monotherapy $(12.5 \mathrm{mg} / \mathrm{kg}$, twice per week). Doxil monotherapies at $3 \mathrm{mg} / \mathrm{kg}$ ( 5 doses) or $9 \mathrm{mg} / \mathrm{kg}$ ( 5 doses) yielded a median time for tumors to reach $1,000 \mathrm{~mm}^{3}$ of 29.9 days (69\% increase) and 43.0 days ( $143 \%$ increase), respectively. The responses to the corresponding combination therapies were more efficacious producing respective median times to 1,000 $\mathrm{mm}^{3}$ of 56.0 days $(216 \%$ increase) and 119.5 days ( $575 \%$ increase) and day 25 synergy scores of 0.6 and 0.4 . The response to Doxil at
$9 \mathrm{mg} / \mathrm{kg}$ with PTC596 was significantly efficacious $(P=0.0360$ by log-rank test).

DTIC monotherapies at $4 \mathrm{mg} / \mathrm{kg}$ ( 3 times per week) or $21 \mathrm{mg} / \mathrm{kg}$ (5 doses) yielded median time for SK-LMS-1 tumors to reach $1,000 \mathrm{~mm}^{3}$ of 18.5 days ( $5 \%$ increase) and 34.7 days ( $96 \%$ increase), respectively. The responses to the corresponding combination therapies were significantly efficacious producing respective median times to 1000 $\mathrm{mm}^{3}$ of 54.7 days ( $209 \%$ increase, $P=0.0144$ by log-rank test) and 165 days ( $832 \%$ increase, $P<0.0010$ by log-rank test) with 5 of 7 tumorfree survivors. Respective synergy scores on day 25 were 0.3 and 0.4 . The response to DTIC at $21 \mathrm{mg} / \mathrm{kg}$ with PTC596 was most effective.

As shown in Supplementary Fig. S4, PTC596 as monotherapy or in combination with Taxotere, DTIC, or Doxil was well-tolerated as shown by the lack of body weight loss. Doxil alone or combined with PTC596 was not tolerated as well as the other regimens in this study, but the addition of PTC596 did not exacerbate the lack of weight gain seen.

\section{PTC596 is efficacious in preclinical models of GBM Orthotopic U-87 MG xenograft model}

As PTC596 crosses the BBB and is distributed into the CNS, it was tested for efficacy in an orthotopic mouse model of human GBM. Temozolomide-sensitive U-87 MG cells were implanted into the cranium of athymic nude mice. Mice were randomized and dosed with vehicle, $20 \mathrm{mg} / \mathrm{kg}$ PTC596 on days 10,17 , and 24 , or with $50 \mathrm{mg} / \mathrm{kg}$ temozolomide orally, daily from days $10-14$. For this study, dosing was not initiated until 10 days after tumor inoculation, resulting in a stringent test of efficacy. As shown in Fig. 5A [body weights in Supplementary Fig. S5A], the median survival time (MST) for vehicle and $50 \mathrm{mg} / \mathrm{kg}$ temozolomide dosed mice was 15 days, indicating that temozolomide was not active. For mice treated with $20 \mathrm{mg} / \mathrm{kg}$ PTC596, the MST was 20 days, a significant $33 \%$ increase in life span relative to vehicle $(P=0.0042$ by log-rank test).

\section{Subcutaneous patient-derived D-09-0500 MG xenograft model}

Efficacy of PTC596 alone and in combination with temozolomide was assessed using the temozolomide-sensitive D-09-0500 MG human GBM tumor xenografts in mice. Mice were administered PTC596 (12 mg/kg, orally, twice per week) and/or temozolomide (25 mg/kg daily from days 3-7). The median time for tumors to reach $1,000 \mathrm{~mm}^{3}$ in vehicle-dosed mice was 10.6 days. In mice treated with PTC596 as monotherapy, the median time to 1,000 $\mathrm{mm}^{3}$ was 37.8 days $(257 \%$ increase). In mice treated with temozolomide as monotherapy, the median time to $1,000 \mathrm{~mm}^{3}$ was significantly delayed over vehicle at 43.4 days (309\% increase, $P<$ 0.0010 by log-rank test) with $1 / 1$ tumor-free survivor (day 147). When PTC596 was combined with temozolomide, the combination was more effective than either agent with the median time for tumors to reach $1,000 \mathrm{~mm}^{3}$ significantly delayed over vehicle at 115.5 days (990\% increase, $P<0.0010$ by log-rank test) and 3 of 3 tumor-free survivors (Fig. 5B). PTC596, temozolomide, or the combination of treatment did not result in decreased body weight (Supplementary Fig. S5B).

\section{Subcutaneous U-87 MG xenograft model}

The 94-day study shown in Fig. 5C-F and Supplementary Table S4 evaluated the efficacy of PTC596 alone and in combination with the chemotherapeutic agents sunitinib, paclitaxel, or temozolomide in the treatment of U-87 MG human GBM tumor xenografts in mice. Body weights are shown in Supplementary Fig. S6. 
A SK-UT-1, PTC596 with Taxotere $(5 \mathrm{mg} / \mathrm{kg})$

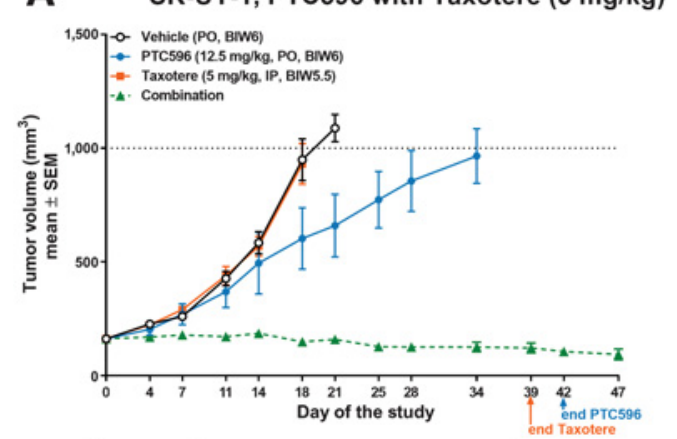

B

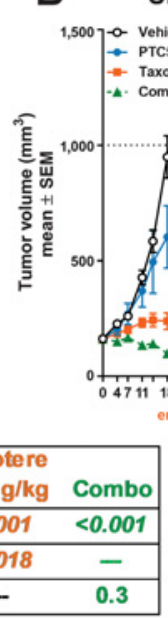

SK-UT-1, PTC596 with Taxotere (15 mg/kg)

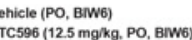

Taxotere (15 mokg, IP, OWE)

combination

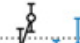

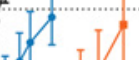

$I^{1}$

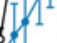

1

1

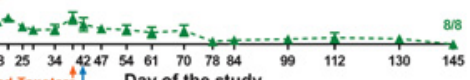
Day of the study end PTC596

\begin{tabular}{|c|ccc|ccc|}
\hline & \multicolumn{5}{|c|}{ Taxotere } & \multicolumn{3}{c|}{ Taxotere } \\
$P$ vs. & PTC596 & $5 \mathrm{mg} / \mathrm{kg}$ & Combo & PTC596 & $15 \mathrm{mg} / \mathrm{kg}$ & Combo \\
\hline Vehicle & 0.0306 & $n s$ & $<0.001$ & 0.0306 & $<0.001$ & $<0.001$ \\
\hline Combo & 0.0106 & $<0.001$ & - & $<0.001$ & 0.0018 & - \\
\hline Synergy & - & - & 0.2 & - & - & 0.3 \\
\hline
\end{tabular}

logrank time-to-endpoint $\left(1,000 \mathrm{~mm}^{3}\right)$

C

SK-LMS-1, PTC596 with Doxil (3 mg/kg)

1,500 7. vehicle (PO, BIW)

- PTC596 (12.5 mg/kg, PO, BiW)

- Doxil (3 mg/kg, IV, aws)

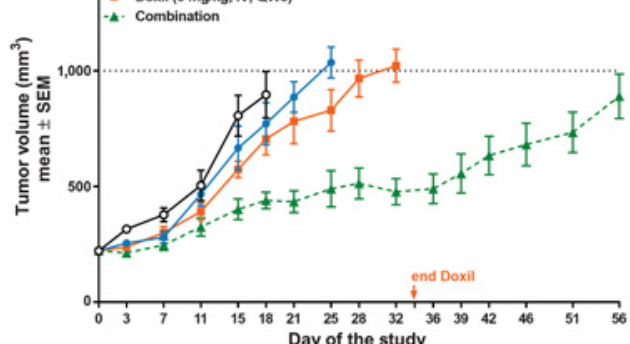

Day of the study

E

SK-LMS-1, PTC596 with DTIC (4 mg/kg)

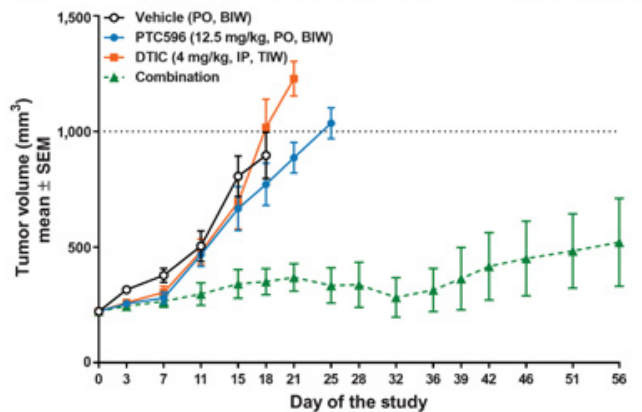

Day of the study
D SK-LMS-1, PTC596 with Doxil (9 mg/kg)

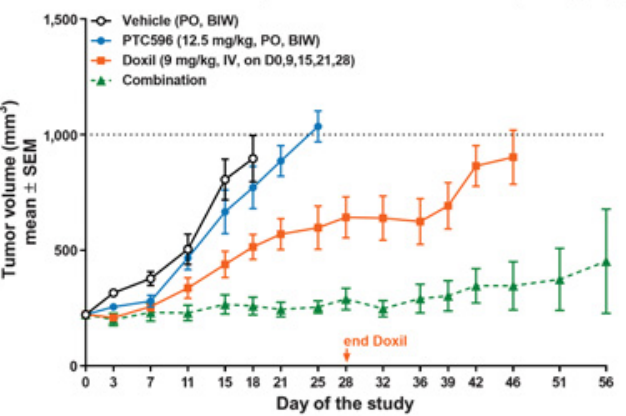

F SK-LMS-1, PTC596 with DTIC $(21 \mathrm{mg} / \mathrm{kg})$

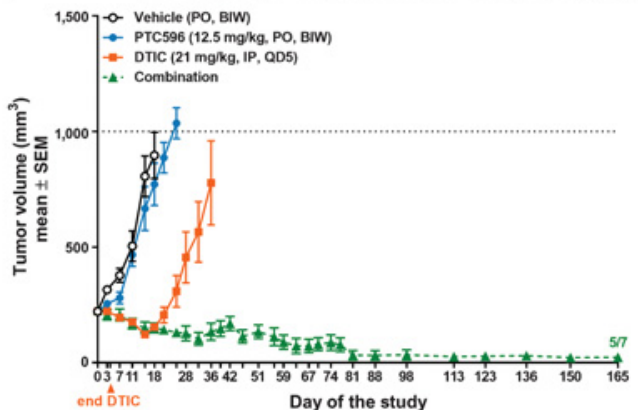

Day of the study

\begin{tabular}{|c|c|c|c|c|c|c|c|c|c|c|}
\hline $\boldsymbol{P}$ vs & PTC596 & $\begin{array}{c}\text { Doxil } \\
\mathrm{mg} / \mathrm{kg}\end{array}$ & Combo & PTC596 & $\begin{array}{c}\text { Doxil } \\
9 \mathrm{mg} / \mathrm{kg}\end{array}$ & Combo & PTC596 & $\begin{array}{c}\text { DTIC } \mathrm{mg} / \mathrm{kg} \\
\text { Combo }\end{array}$ & PTC596 \\
\hline Vehicle & $n s$ & $n s$ & $n s$ & $n s$ & $n s$ & 0.0360 & $n s$ & $n s$ & 0.0144 & $n s$ \\
\hline Combo & $<0.001$ & $<0.001$ & - & 0.0054 & $n s$ & - & $<0.001$ & $<0.001$ & - & $<0.001$ \\
\hline
\end{tabular}

logrank time-to-endpoint $\left(1,000 \mathrm{~mm}^{3}\right)$

Figure 4.

Growth of human leiomyosarcoma xenografts in mice administered taxotere, Doxil, or DTIC as single agents or combined with PTC596. Symbols represent the mean tumor volumes $\left(\mathrm{mm}^{3}\right) \pm$ SEM. The $1,000 \mathrm{~mm}^{3}$ tumor volume endpoint is shown as a horizontal dotted line. Mean tumor growth curves are truncated on the first day that $\geq 50 \%$ of the animals in a group attained the endpoint tumor volume. As shown in the inset tables, the log-rank test was employed to assess the significance of the difference in the distribution of time-to-endpoint (time to $1,000 \mathrm{~mm}^{3}$ or death in days) values for mono and combination therapy groups versus vehicle or combination therapy groups with $P$ values corrected for multiple comparisons. In addition, a Synergy score $<0.7$ for the combination therapy indicated synergy compared to the corresponding monotherapies. A and B, Male athymic nude mice were inoculated subcutaneously with SK-UT-1 tumor cells. Nine days after tumor inoculation, mice were randomized by tumor volume into groups of 10 mice each and treated with PTC596 and Taxotere alone or combined. At day 0 , all groups had 10 mice/group. C-F, Male athymic nude mice were implanted subcutaneously in the right flank with SK-LMS-1 tumor fragments. Ten days after tumor inoculation, mice were randomized by tumor volume into groups of 8 mice each and treated with PTC596 and Doxil (C and D) alone or combined or with PTC596 and DTIC (E and F) alone or combined. At day 0 , all groups had 8 mice/group. Abbreviations: Ratios are TFS/SS, the number of animals that survived the study with tumors too small to measure (TFS)/the number of animals remaining at study end (SS). 
A

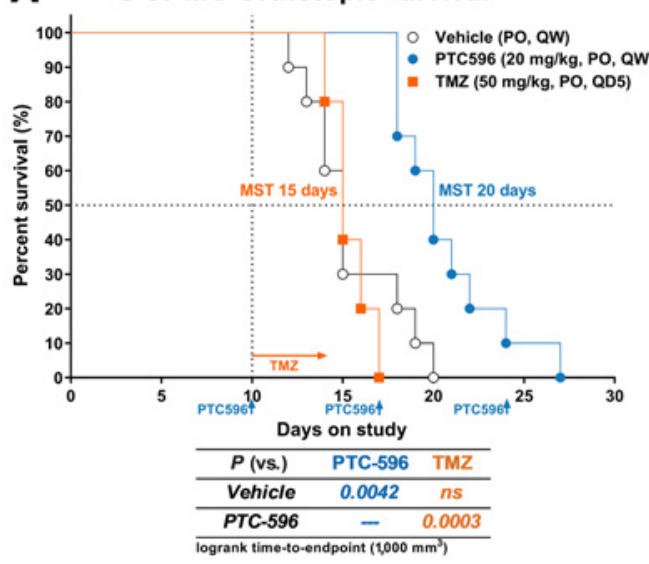

B D-09-0500 MG GBM tumor xenograft

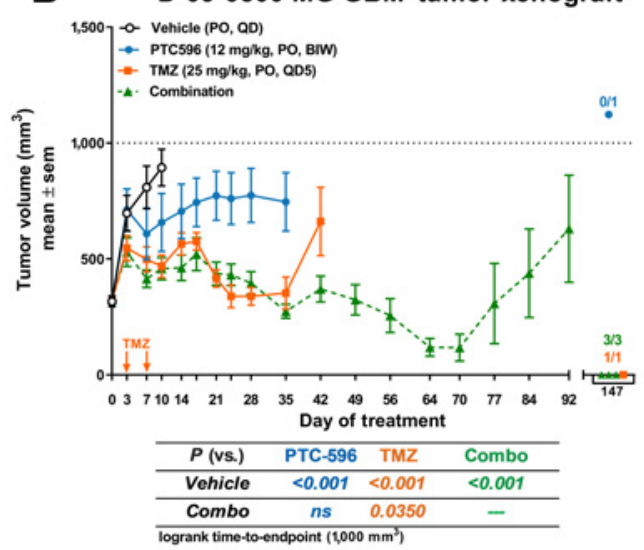

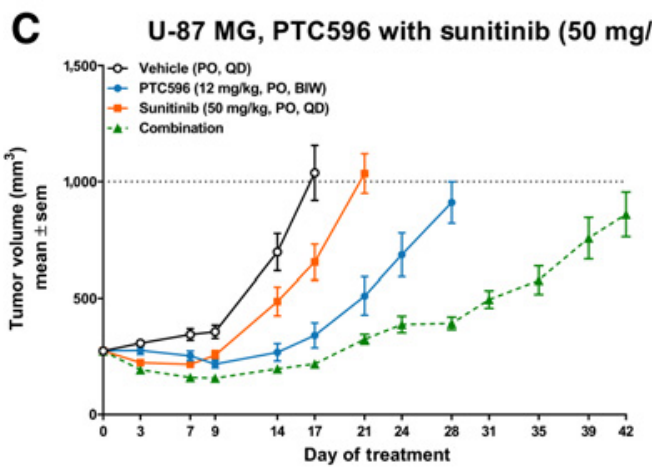

D U-87 MG, PTC596 with paclitaxel (15 mg/kg)

\section{1,500 T- Vehicle (PO, QD)}

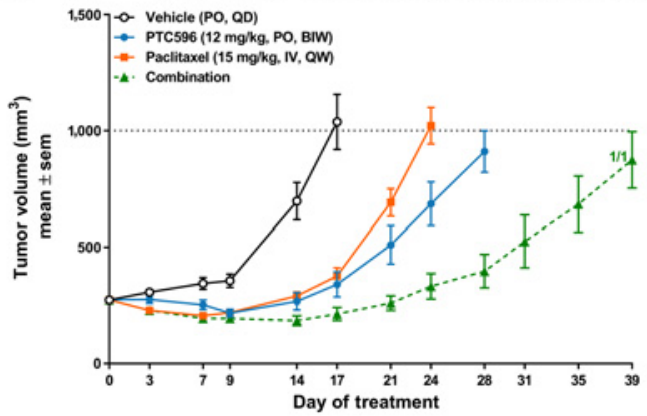

E U-87 MG, PTC596 with TMZ $(2.5 \mathrm{mg} / \mathrm{kg})$

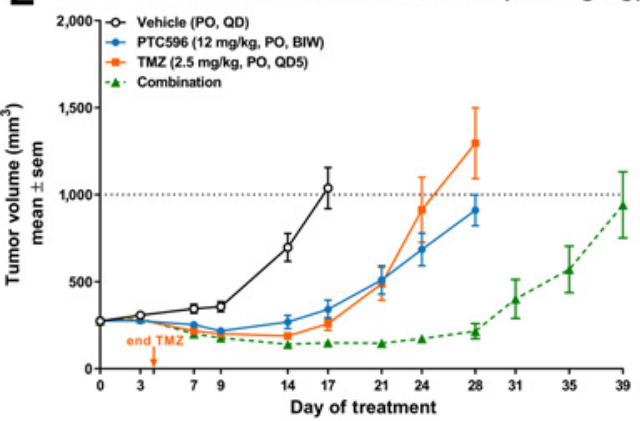

F U-87 MG, PTC596 with TMZ $(5 \mathrm{mg} / \mathrm{kg})$

F $1,500-100$ vencict $(P 0,00)$

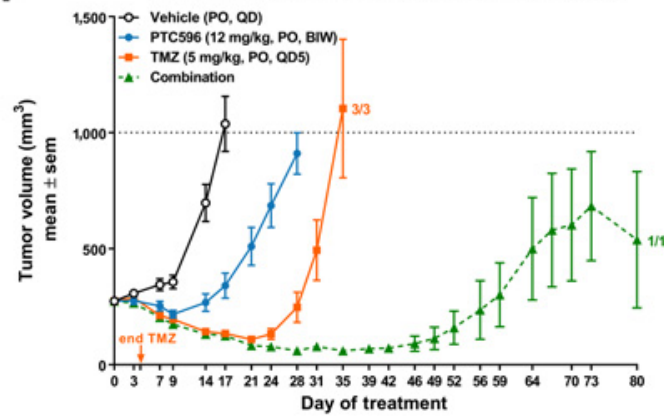

\begin{tabular}{|l|ccc|ccc|ccc|ccc|}
\hline $\boldsymbol{P}$ vs. & PTC-596 & $\begin{array}{c}\text { Sunitinib } \\
50 \mathrm{mg} / \mathrm{kg}\end{array}$ & Combo & PTC-596 & $\begin{array}{c}\text { Paclitaxel } \\
15 \mathrm{mg} / \mathrm{kg}\end{array}$ & Combo & PTC-596 & $\begin{array}{c}\text { TMZ } \\
2.5 \mathrm{mg} / \mathrm{kg}\end{array}$ & Combo & PTC-596 & $\begin{array}{c}\text { TMZ } \\
5 \mathrm{mg} / \mathrm{kg}\end{array}$ & Combo \\
\hline Vehicle & $<0.001$ & 0.0024 & $<0.001$ & $<0.001$ & $<0.001$ & $<0.001$ & $<0.001$ & $<0.001$ & $<0.001$ & $<0.001$ & $<0.001$ & $<0.001$ \\
\hline Combo & 0.0012 & $<0.001$ & - & 0.0030 & $<0.001$ & - & 0.0036 & 0.0036 & - & $<0.001$ & ND & - \\
\hline
\end{tabular}

logrank time-to-endpoint $\left(1,000 \mathrm{~mm}^{3}\right)$

Figure 5.

Growth of human GBM xenografts in mice administered temozolomide as a single agent or combined with PTC596. Symbols represent the mean tumor volumes $\left(\mathrm{mm}^{3}\right) \pm$ SEMs. The $1,000 \mathrm{~mm}^{3}$ tumor volume endpoint is shown as a horizontal dotted line. Mean tumor growth curves are truncated on the first day that $\geq 50 \%$ of the animals in a group attained the endpoint tumor volume. As shown in the inset tables, the log-rank test was employed to assess the significance of the difference in the distribution of time-to-endpoint (time to $1,000 \mathrm{~mm}^{3}$ or death in days) values for mono and combination therapy groups versus vehicle or combination therapy groups with $P$ values corrected for multiple comparisons. Synergy was not evaluated due to the rapid growth of tumors in vehicle control animals. A, Female athymic nude mice were inoculated intracranially with U-87 MG tumor cells $\left(2 \times 10^{5}\right)$. Ten days after tumor inoculation, animals were randomized into groups of 10 mice each and treatments initiated as shown. B, D-09-0500 MG tumors were removed from host animals under sterile conditions, homogenized into a cell suspension, and injected subcutaneously into the right flank of athymic nude mice. Ten days after tumor inoculation, mice were randomized by tumor volume (average tumor volume was $\sim 321 \mathrm{~mm}^{3}$ ) into groups of 9 mice each and treatment was initiated as shown. C-F, Male athymic nude mice were inoculated subcutaneously in the flank with U-87 MG tumor cells $\left(5 \times 10^{6}\right.$ cells in $0.2 \mathrm{~mL}$ with $50 \%$ Matrigel). Twelve days after tumor inoculation, mice were randomized by tumor volume into groups of 10 mice each that were treated with PTC596 and sunitinib alone or combined (C) or with paclitaxel alone or combined (D), or with TMZ alone or combined (E and F). At day 0, all groups had 10 mice/group. Abbreviations: MST, median survival times; Ratios are TFS/SS, the number of animals that survived the study with tumors too small to measure (tumor-free survivors; TFS) / the number of animals remaining at study end (study survivors; SS). TMZ, temozolomide. 
The median time for tumors to reach $1,000 \mathrm{~mm}^{3}$ was 16.0 days in vehicle-dosed mice. In mice dosed with PTC596 monotherapy (12 mg/kg, twice per week, orally), the median time to $1,000 \mathrm{~mm}^{3}$ was significantly delayed over vehicle at 28.1 days (76\% increase, $P<$ 0.0010 by log-rank test). Sunitinib $(50 \mathrm{mg} / \mathrm{kg}$, once daily, orally) and paclitaxel $(15 \mathrm{mg} / \mathrm{kg}$, once-per-week, i.v.) monotherapies yielded significant delays in median times to $1,000 \mathrm{~mm}^{3}$ of 20.7 days $(29 \%$ increase, $P=0.0024$ by log-rank test) and 23.7 days ( $49 \%$ increase, $P$ $<0.0010$ by log-rank test), respectively. The responses to the corresponding combination therapies were more efficacious producing respective significant delays in median times to $1,000 \mathrm{~mm}^{3}$ of 40.5 days $(154 \%$ increase, $P<0.0010$ by log-rank test) and 39.3 days $(146 \%$ increase, $P<0.0010$ by log-rank test, $1 / 1$ tumorfree survivor).

In mice dosed with temozolomide monotherapy at 2.5 and $5 \mathrm{mg} / \mathrm{kg}$ the median times to reach $1,000 \mathrm{~mm}^{3}$ were 25.0 days ( $57 \%$ increase) and 33.0 days ( $107 \%$ increase, $3 / 3$ tumor-free survivors at day 94 ), respectively. In mice treated with the combination, the median time for the tumor volume to reach $1,000 \mathrm{~mm}^{3}$ was 37.2 days ( $133 \%$ increase) and 76.9 days (382\% increase, $1 / 1$ tumor-free survivor). All temozolomide treatment regimens were significantly efficacious $(P<0.0010$ by log-rank test) but the combination of temozolomide at $5 \mathrm{mg} / \mathrm{kg}$ with PTC596 was most effective.

PTC596 plasma exposures in phase I trial of patients with advanced solid tumors exceed concentrations associated with efficacy in preclinical models

Before initiating phase I clinical studies, Investigational New Drug (IND) -enabling toxicology and drug absorption, distribution, and metabolism studies were performed to support the clinical program. Pharmacokinetics of PTC596 was evaluated in the mouse, rat, and monkey (Supplementary Fig. S7). Good Laboratory Practice (GLP) 28-day studies were performed in the rat and monkey. As shown, the dose-normalized absolute oral bioavailability (F\%) in rats was $>79 \%$ after a single dose at $10 \mathrm{mg} / \mathrm{kg}$ and was $66 \%$ at $2 \mathrm{mg} / \mathrm{kg}$ in cynomolgus monkeys.

A 28-day phase I, open-label, first-in-human, safety and pharmacokinetic study of PTC596 as monotherapy was conducted in 31 patients with advanced solid tumors. This work has been described in more detail in another publication (39). The median age was 62.5 years (range 27 to 81 years) and approximately $60 \%$ were female. Patients received eight doses per 4-week cycle schedule. GLP and nonGLP studies indicated that $40 \mathrm{mg} / \mathrm{kg}$ twice per week was approximately the severely toxic dose in $10 \%$ of rats (STD 10). Therefore, the starting dose in the phase I study was calculated as one-tenth of the human equivalent dose (HED) of $40 \mathrm{mg} / \mathrm{kg}$ twice per week in rats, which was $0.65 \mathrm{mg} / \mathrm{kg}$ twice per week. Doses were increased to a maximum dose of $10 \mathrm{mg} / \mathrm{kg}$.

Exposures measured in mice were compared with exposures measured in humans. As discussed previously, 12 or $12.5 \mathrm{mg} / \mathrm{kg}$ PTC596 was utilized for combination testing in the mouse. In the mouse, a dose of $12.5 \mathrm{mg} / \mathrm{kg}$ was predicted to result in a $C_{\max }$ of $1,445 \mathrm{ng} / \mathrm{mL}$. If efficacy is assumed to be related to the total drug concentration at the $C_{\max }$, the human dose that correlates to the mouse $C_{\max }(1,445 \mathrm{ng} / \mathrm{mL}$ ) is $3.6 \mathrm{mg} / \mathrm{kg}$ (Fig. 6A). If efficacy is correlated to the $f C_{\max }$, the predicted human dose is $1.6 \mathrm{mg} / \mathrm{kg}$ because protein binding is higher in mice (99.5\% protein bound) than in humans ( $99.2 \%$ protein bound). The predicted human dose based on $\mathrm{AUC}_{\text {last }}$ and free $\mathrm{AUC}_{\text {last }}\left(f \mathrm{AUC} \mathrm{C}_{\text {last }}\right)$ values in the mouse are $3.9 \mathrm{mg} / \mathrm{kg}$ and $2.3 \mathrm{mg} / \mathrm{kg}$, respectively. The target exposures of $1,445 \mathrm{ng} / \mathrm{mL}$ in mice and 24,065 hour* $\mathrm{ng} / \mathrm{mL}$ in humans are shown as horizontal dashed lines in Fig. 6B. As predicted, these parameters fall between those attained at single doses of PTC596 at 2.6 and $5.2 \mathrm{mg} / \mathrm{kg}$ that yielded $C_{\max }$ values of 1,261 and $1,727 \mathrm{ng} / \mathrm{mL}$ and $\mathrm{AUC}_{\text {last }}$ values of 18,271 and 29,563 hour*ng/mL, respectively. As shown in Fig. 6C, there were mixed/partial responses or stable disease in $23 \%(7 / 31)$ of patients.

\section{Discussion}

PTC596 is an investigational orally bioavailable small molecule that binds to tubulin, a validated target for cancer treatment. PTC596 binds to the colchicine site of tubulin via unique key interactions previously unobserved with other agents that bind to the colchicine site. As an amine substituted pyrimidine compound that lacks the trimethoxyphenyl moiety, PTC596 is structurally and pharmacologically different than other tubulin-binding agents.

Crystallographic studies showed that the overall structure of tubulin in the $\mathrm{T}_{2} \mathrm{R}$-TTL-PTC596 complex superimposed well with the apo structure, suggesting that binding of PTC596 does not affect the overall conformation of tubulin except for a difference in the orientation of the $\beta$ T7-loop residues in the holo- versus the apo-state. Comparing the binding mode of PTC596 with that of colchicine showed that the major difference between PTC596 and colchicine in occupied space in the binding site is caused by the absence of the colchicine acetamidegroup, which results in a flip of both the $\beta \mathrm{T} 7$ - and the $\alpha \mathrm{T} 5$-loops and the side chain orientation of $\beta$ Lys352. Colchicine site ligands are well known to destabilize microtubules by inhibiting the curved-tostraight conformational transition that tubulin dimers undergo during microtubule formation ((40); reviewed in (1)). Free tubulin assumes a "curved" conformation while tubulin in the microtubule lattice is "straight". Colchicine-site ligands inhibit the curved-tostraight conformational transition that tubulin dimers must undergo to form microtubules; they thus typically act as microtubuledestabilizing agents (reviewed in (1). Our structural and computational information obtained on PTC596 and its two derivatives suggests that this class of tubulin-binding agents destabilizes microtubules by a similar molecular mechanism.

Differences in the kinetics of binding to tubulin will likely affect the side-effect profile of colchicine site ligands. The binding mechanism of PTC596 may be correlated with the lack of neuropathy seen in clinical trials to date.

PTC596 exhibited broad-spectrum activity in vitro across tumor cell lines with different driving mutations. Activity against leiomyosarcoma and GBM were further evaluated in a series of xenograft studies. For both types of cancers, there are no consistent driving mutations leading to ineffective treatment with targeted therapy. Furthermore, both diseases tend to have low mutational burden, and to date have not been amenable to immuno-oncology approaches.

In mouse xenograft studies using the human SK-UT-1 and SKLMS-1 cell line models of LMS, PTC596 in combination with SOC agents Taxotere, Doxil, and DTIC were well tolerated and significantly more efficacious than the responses to the corresponding monotherapies. PTC596 exhibited strong synergy when combined with these agents. On the basis of the promising preclinical data in leiomyosarcoma, a clinical trial assessing PTC596 in combination with DTIC in leiomyosarcoma is underway.

In contrast to many tubulin-binding agents, PTC596 is not a substrate for P-gp and crosses the BBB making it an attractive candidate for a broad number of oncological indications, including neuro-oncology. In a stringent test of efficacy in an orthotopic mouse 
PTC596 is a Novel Oral Tubulin Inhibitor That Crosses the BBB

A Comparing PK parameters in mouse versus human

\begin{tabular}{|c|c|c|c|c|c|c|}
\hline PK Parameter & $\begin{array}{c}\text { Mouse PK } \\
\text { @10 mg/kg } \\
\text { PTC596 }\end{array}$ & $\begin{array}{c}\text { Predicted mouse } \\
\text { PK } \\
\text { @12.5 mg/kg }\end{array}$ & $\begin{array}{l}\text { Efficacy } \\
\text { correlation }\end{array}$ & $\begin{array}{c}\text { PK } \\
\text { parameter }\end{array}$ & $\begin{array}{c}\text { Target human PK } \\
\text { @12.5 mg/kg PTC596 }\end{array}$ & $\begin{array}{c}\text { Predicted } \\
\text { human dose } \\
(\mathrm{mg} / \mathrm{kg})\end{array}$ \\
\hline$f \mathrm{C}_{\max }(n g / m L)$ & 5.8 & 7.2 & $f \mathrm{C}_{\max }$ & $\mathrm{C}_{\max }$ & 903 & 1.6 \\
\hline fAUC (hr.ng/mL) & 96 & 120 & fAUC & AUC $_{\text {last }}$ & 15041 & 2.3 \\
\hline $\mathrm{C}_{\max }(\mathrm{ng} / \mathrm{mL})$ & 1156 & 1445 & $\mathrm{C}_{\max }$ & $\mathrm{C}_{\max }$ & 1445 & 3.6 \\
\hline AUC $_{\text {last }}(\mathrm{hr} . \mathrm{ng} / \mathrm{mL}$ ) & 19252 & 24065 & AUC $_{\text {last }}$ & AUC $_{\text {last }}$ & 24065 & 3.9 \\
\hline
\end{tabular}

\section{B PK Parameters from clinical trial patients}

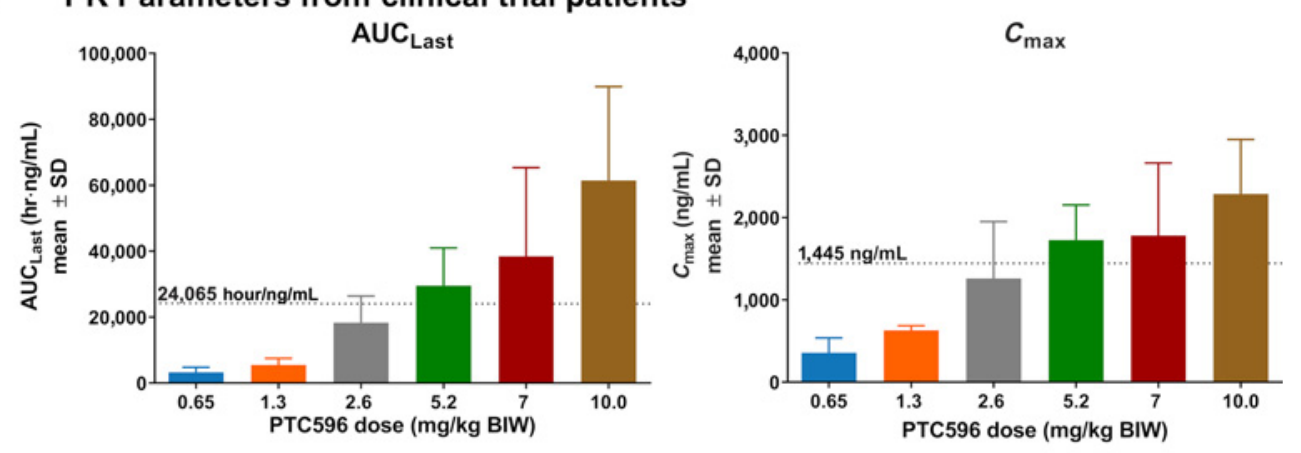

\section{A 28-day phase I study of PTC596 as monotherapy}

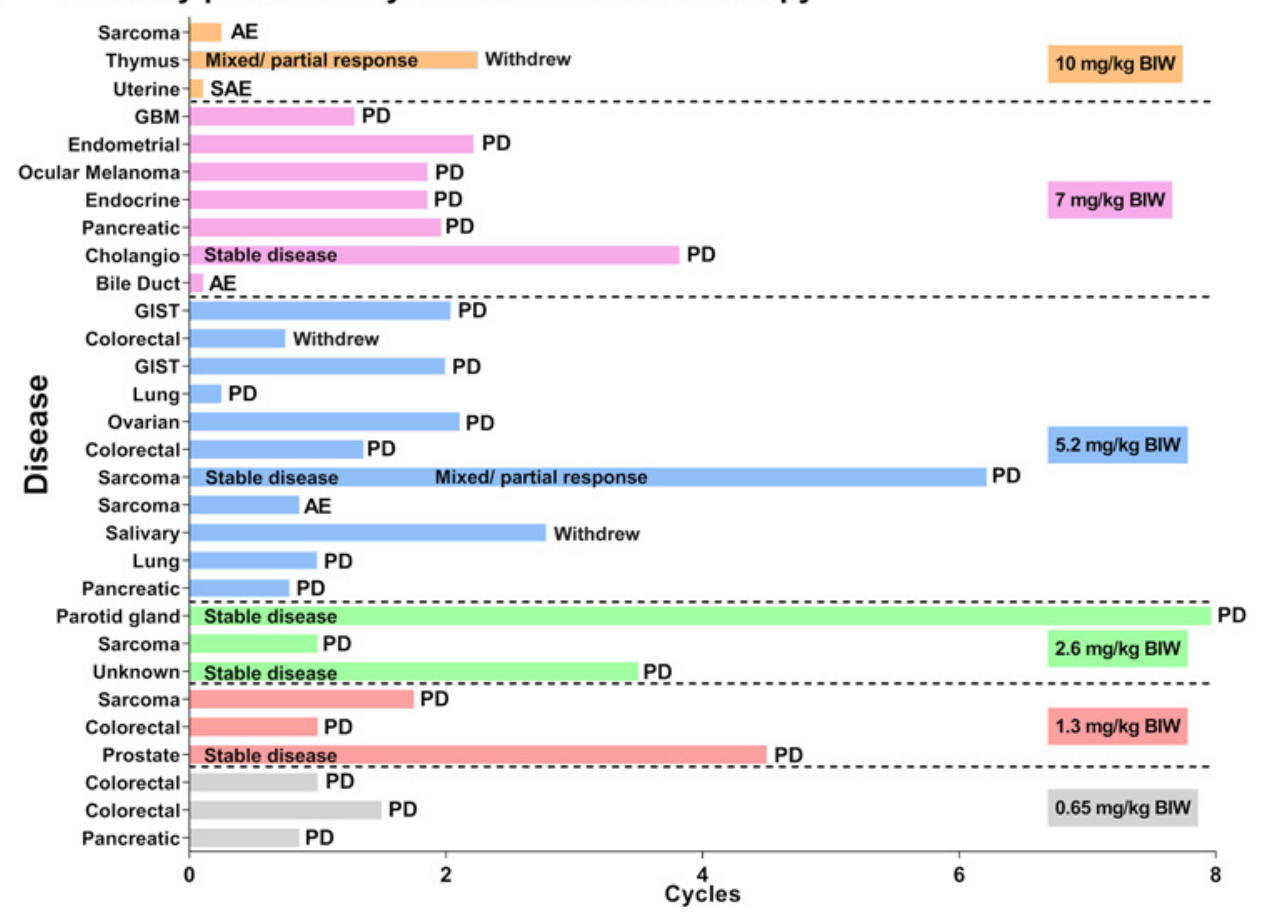

Figure 6.

Pharmacokinetics of PTC596 in patients with cancer (day 1, cycle 1) and duration of treatment. A, Data from mouse studies were compared with the pharmacokinetic parameters and dose in humans. In the mouse, $C_{\max }$ and $A U C_{\text {last }}$ values for a dose of $12.5 \mathrm{mg} / \mathrm{kg}$ were predicted as values measured at $10 \mathrm{mg} / \mathrm{kg} \times 1.25$. These predicted $C_{\max }$ and $A U C_{\text {last }}$ values for a dose of $12.5 \mathrm{mg} / \mathrm{kg}$ were set as $C_{\max }$ and $A U C_{\text {last }}$-driven targets in the human. In the mouse, $99.5 \%$ of the PTC596 is protein bound, so free $C_{\max }\left(f C_{\text {max }}\right)$ and free $A U C_{\text {last }}\left(f A U C_{\text {last }}\right)$ values for a dose of $12.5 \mathrm{mg} / \mathrm{kg}$ were predicted as values measured at $10 \mathrm{mg} / \mathrm{kg} \times 0.005 \times 1.25$. The predicted $f C_{\max }$ and $f A U C_{\text {last }}$ values for a dose of $12.5 \mathrm{mg} / \mathrm{kg}$ were adjusted for reduced protein binding in humans (99.2\%) and defined as $f C_{\text {max }}$ and $f A U C_{\text {last }}$ targets in the human. The predicted human dose for each pharmacokinetic parameter was determined from regression analysis using the human pharmacokinetic dataset from the phase I trial. B, The pharmacokinetic parameters $A \cup C_{\text {last }}$ and $C_{\max }$ were determined in plasma samples collected from the enrolled patients with cancer on day 1 , cycle 1. Previous preclinical efficacy studies demonstrated that inhibition of tumor growth was associated with an $A \cup C_{\text {last }}$ of $24,065 \mathrm{hr} / \mathrm{ng} / \mathrm{mL}$ and a $C_{\text {max }}$ of $1,445 \mathrm{ng} / \mathrm{mL}$ at $12.5 \mathrm{mg} / \mathrm{kg}$ in the mouse (horizontal dashed lines). C, A 28-day phase I study of PTC596 as monotherapy was conducted in 31 patients with different types of advanced solid tumors. The median age was 62.5 years (range 27 to 81 years) and approximately $60 \%$ were female. The objective of the study was to characterize any antitumor activity and associated adverse effects of PTC596 orally administered on a twice weekly schedule (8 doses per 4-week cycle). Response was evaluated every other treatment cycle according to RECIST or RANO criteria. Abbreviations: PD, progressive disease; AE, adverse event; SAE, serious adverse event. 
model of GBM, PTC596 as monotherapy significantly prolonged survival even when initiation of treatment was delayed until day 10 , while temozolomide administered at its MTD did not. This demonstrated that PTC596 readily crosses the BBB. In mouse xenograft studies using a patient-derived model and a U-87 MG human cell line model of GBM, PTC596 in combination with SOC agents sunitinib, paclitaxel, or temozolomide were acceptably tolerated and significantly more efficacious than the responses to the corresponding monotherapies. On the basis of these promising preclinical data in GBM, a clinical trial in diffuse intrinsic pontine glioma (DIPG) is ongoing. DIPG is a childhood brain tumor with significant unmet need and a 5 -year survival rate of less than $2.2 \%$ (41).

In a series of dose-optimization and pharmacokinetic studies in mice, a dosing regimen of $12.5 \mathrm{mg} / \mathrm{kg}$, orally, twice per week was utilized on the basis of the observation that there was no significant improvement in response with more frequent dosing. Furthermore, a dose of $12.5 \mathrm{mg} / \mathrm{kg}$ PTC596 still allowed for detection of additive/ synergistic combinations with standard of care drugs. The data indicate that efficacy correlated with the $C_{\max }$ rather than with the AUC. On the basis of these data, the twice per week dosing regimen was used in the IND-enabling toxicology and in the completed and ongoing clinical trials. Most tubulin-binding agents are administered by intravenous infusion and therefore the pharmacokinetic profile and subsequent pharmacodynamic profile would likely differ for drugs that are administered intravenously compared with oral administration. Therefore, oral administration in addition to providing convenience to the patient, may also result in a different pharmacodynamic profile.

The human dose that correlated to the $C_{\max }(1,445 \mathrm{ng} / \mathrm{mL})$ associated with a dose of $12.5 \mathrm{mg} / \mathrm{kg}$ in the mouse was $3.6 \mathrm{mg} / \mathrm{kg}$ if efficacy was assumed to be related to the total drug concentration or $1.6 \mathrm{mg} / \mathrm{kg}$ if correlated to the free $C_{\max }$, based on differences in protein binding. The initial results from a phase Ib clinical trial showed that PTC596 monotherapy reached plasma exposures predicted to be efficacious in mouse models.

In summary, PTC596 is an investigational orally bioavailable small molecule that binds to tubulin at the colchicine binding site utilizing pockets of the binding site not targeted by other tubulin-binding agents. In contrast to many tubulin-binding agents, PTC596 is not a substrate for P-gp, has compelling pharmacologic properties including a long circulating half-life and effective biodistribution into tumors, and crosses the blood-brain-barrier, making it an attractive candidate for many oncologic indications including neuro-oncology. PTC596

\section{References}

1. Steinmetz MO, Prota AE. Microtubule-targeting agents: strategies to hijack the cytoskeleton. Trends Cell Biol 2018;28:776-92.

2. Bennett MJ, Barakat K, Huzil JT, Tuszynski J, Schriemer DC Discovery and characterization of the laulimalide-microtubule binding mode by mass shift perturbation mapping. Chem Biol 2010;17: 725-34.

3. Field JJ, Díaz JF, Miller JH. The binding sites of microtubule-stabilizing agents. Chem Biol 2013;20:301-15.

4. Li L, Jiang S, Li X, Liu Y, Su J, Chen J. Recent advances in trimethoxyphenyl (TMP) based tubulin inhibitors targeting the colchicine binding site. Eur J Med Chem 2018;151:482-94.

5. Mukhtar E, Adhami VM, Mukhtar H. Targeting microtubules by natural agents for cancer therapy. Mol Cancer Ther 2014;13:275-84.

6. Perez EA. Microtubule inhibitors: differentiating tubulin-inhibiting agents based on mechanisms of action, clinical activity, and resistance. Mol Cancer Ther 2009; 8:2086-95. exhibits broad-spectrum anticancer activity alone or in combination with SOC agents. Here, we showed that in both leiomyosarcoma and GBM preclinical models, PTC596, alone or combined with SOCs, exhibited notable efficacy and that efficacy was synergistic with chemotherapy agents. In a phase I trial, PTC596 caused no DLTs at doses predicted to be efficacious based on mouse models, providing strong support for continued clinical development for treating solid tumors. PTC596 is currently being tested in combination with radiation in a clinical trial in children with diffuse intrinsic pontine glioma and in combination with dacarbazine in a clinical trial in adults with leiomyosarcoma.

\section{Authors' Disclosures}

No disclosures were reported.

\section{Authors' Contributions}

F. Jernigan: Conceptualization, software, formal analysis, investigation, methodology, writing-original draft. A. Branstrom: Conceptualization, resources, data curation, formal analysis, supervision, investigation, writing-original draft. J.D. Baird: Conceptualization, resources, writing-review and editing. L. Cao: Conceptualization, resources, data curation, supervision, investigation. M. Dali: Resources, methodology. B. Furia: Investigation. M. Kim: Data curation, investigation. K. O'Keefe: Conceptualization, resources, supervision, funding acquisition. R. Kong: Resources, supervision, investigation. O.L. Laskin: Conceptualization, data curation. J.M. Colacino: Resources, funding acquisition, writing-review and editing. M. Pykett: Supervision, funding acquisition. A. Mollin: Data curation, investigation, methodology. J. Sheedy: Investigation, methodology. M. Dumble: Conceptualization, investigation, methodology. Y. Moon: Conceptualization, resources, formal analysis, supervision, visualization, writing-review and editing. R. Sheridan: Data curation, formal analysis, writing-original draft. T. Mühlethaler: Software, investigation, methodology. R.J. Spiegel: Conceptualization, resources, funding acquisition. A.E. Prota: Conceptualization, data curation, software, investigation, methodology. M. Steinmetz: Conceptualization, resources, formal analysis, writing-original draft, writing-review and editing. M. Weetall: Conceptualization, resources, data curation, supervision, funding acquisition, visualization, writing-original draft.

\section{Acknowledgments}

The authors thank Brenda Tiffin for writing support. The work was funded by PTC Therapeutics, Inc. and the Wellcome Trust, award \#092687.

The costs of publication of this article were defrayed in part by the payment of page charges. This article must therefore be hereby marked advertisement in accordance with 18 U.S.C. Section 1734 solely to indicate this fact.

Received September 6, 2020; revised January 20, 2021; accepted June 9, 2021; published first July 26, 2021.
7. Yano K, Tomono T, Ogihara T. Advances in studies of p-glycoprotein and its expression regulators. Biol Pharm Bull 2018;41:11-19.

8. Leonard GD, Fojo T, Bates SE. The role of ABC transporters in clinical practice. Oncologist 2003;8:411-24

9. Waghray D, Zhang Q. Inhibit or evade multidrug resistance p-glycoprotein in cancer treatment. J Med Chem 2018;61:5108-21.

10. van Tellingen O, Kuijpers AV, Beijnen JH, Nooijen WJ, Bult A. Plasma pharmacokinetics, tissue disposition, excretion and metabolism of vinorelbine in mice as determined by high performance liquid chromatography. Invest New Drugs 1993;11:141-50.

11. Sparreboom A, van Asperen J, Mayer U, Schinkel AH, Smit JW, Meijer DK, et al Limited oral bioavailability and active epithelial excretion of paclitaxel (Taxol) caused by P-glycoprotein in the intestine. Proc Natl Acad Sci U S A 1997;94: 2031-5.

12. Jibodh RA, Lagas JS, Nuijen B, Beijnen JH, Schellens JH. Taxanes: old drugs, new oral formulations. Eur J Pharmacol 2013;717:40-46. 
13. Hagiwara H, Sunada Y. Mechanism of taxane neurotoxicity. Breast Cancer 2004; $11: 82-85$.

14. Velasco R, Bruna J. Taxane-induced peripheral neurotoxicity. Toxics 2015;3: 152-69.

15. Pease-Raissi SE, Pazyra-Murphy MF, Li Y, Wachter F, Fukuda Y, Fenstermacher SJ, et al. Paclitaxel reduces axonal bclw to initiate IP(3)R1-dependent axon degeneration. Neuron 2017;96:373-86.

16. Ciruelos E, Apellániz-Ruiz M, Cantos B, Martinez-Jáñez N, Bueno-Muiño C, Echarri MJ, et al. A pilot, phase II, randomized, open-label clinical trial comparing the neurotoxicity of three dose regimens of nab-paclitaxel to that of solvent-based paclitaxel as the first-line treatment for patients with human epidermal growth factor receptor type 2-negative metastatic breast cancer. Oncologist 2019;24:e1024-33.

17. Kim MJ, Cao L, Sheedy J, Risher N, Dumble M, Lee C-S, et al. PTC596-induced BMI1 hyper-phosphorylation via CDK1/2 activation resulting in tumor stem cell depletion [abstract]. In: Proceedings of the 105th Annual Meeting of the American Association for Cancer Research; 2014 Apr 5-9; San Diego, CA Philadelphia (PA): AACR; 2014. Abstract nr 5517.

18. Nishida Y, Maeda A, Kim M, Cao L, Kubota Y, Ishizawa J, et al. The novel BMI-1 inhibitor PTC596 downregulates MCL-1 and induces p53-independent mitochondrial apoptosis in acute myeloid leukemia progenitor cells. Blood Cancer J 2017;7:e527.

19. Eberle-Singh JA, Sagalovskiy I, Maurer HC, Sastra SA, Palermo CF, Decker AR, et al. Effective delivery of a microtubule polymerization inhibitor synergizes with standard regimens in models of pancreatic ductal adenocarcinoma. Clin Cancer Res 2019;25:5548-60.

20. Prota AE, Bargsten K, Zurwerra D, Field JJ, Díaz JF, Altmann KH, et al. Molecular mechanism of action of microtubule-stabilizing anticancer agents. Science 2013; 339:587-90.

21. Prota AE, Magiera MM, Kuijpers M, Bargsten K, Frey D, Wieser M, et al Structural basis of tubulin tyrosination by tubulin tyrosine ligase. J Cell Biol 2013; 200:259-70.

22. Kabsch W. XDS. Acta Crystallogr D Biol Crystallogr 2010;66:125-32.

23. Brown KE, Chagoya G, Kwatra SG, Yen T, Keir ST, Cooter M, et al. Proteomic profiling of patient-derived glioblastoma xenografts identifies a subset with activated EGFR: implications for drug development. J Neurochem 2015;133: 730-8.

24. Ishii T, Seike T, Nakashima T, Juliger S, Maharaj L, Soga S, et al. Anti-tumor activity against multiple myeloma by combination of KW-2478, an Hsp90 inhibitor, with bortezomib. Blood Cancer J 2012;2:e68.

25. U.S. Food and Drug Administration. Guidance for industry: S9 nonclinical evaluation for anticancer pharmaceuticals; 2010.

26. Le Tourneau C, Lee JJ, Siu LL. Dose escalation methods in phase I cancer clinical trials. J Natl Cancer Inst 2009;101:708-20.

27. Bohnert T, Gan LS. Plasma protein binding: from discovery to development. J Pharm Sci 2013;102:2953-94.

28. Smith DA, Di L, Kerns EH. The effect of plasma protein binding on in vivo efficacy: misconceptions in drug discovery. Nat Rev Drug Discov 2010;9:929-39.
29. Toro JR, Travis LB, Wu HJ, Zhu K, Fletcher CD, Devesa SS. Incidence patterns of soft tissue sarcomas, regardless of primary site, in the surveillance, epidemiology and end results program, 1978-2001: an analysis of 26,758 cases. Int J Cancer 2006;119:2922-30.

30. Ducimetière F, Lurkin A, Ranchère-Vince D, Decouvelaere A-V, Péoc'h M, Istier $\mathrm{L}$, et al. Incidence of sarcoma histotypes and molecular subtypes in a prospective epidemiological study with central pathology review and molecular testing. PLoS One 2011;6:e20294.

31. Ferrari A, Sultan I, Huang TT, Rodriguez-Galindo C, Shehadeh A, Meazza C, et al. Soft tissue sarcoma across the age spectrum: a population-based study from the Surveillance Epidemiology and End Results database. Pediatr Blood Cancer 2011;57:943-9.

32. Friedman CF, Hensley ML. Options for adjuvant therapy for uterine leiomyosarcoma. Curr Treat Options Oncol 2018;19:7.

33. Nagar SP, Mytelka DS, Candrilli SD, D’Yachkova Y, Lorenzo M, Kasper $\mathrm{B}$, et al. Treatment patterns and survival among adult patients with advanced soft tissue sarcoma: a retrospective medical record review in the United Kingdom, Spain, Germany, and France. Sarcoma 2018;2018: 5467057.

34. Parikh RC, Lorenzo M, Hess LM, Candrilli SD, Nicol S, Kaye JA. Treatment patterns and survival among older adults in the United States with advanced softtissue sarcomas. Clin Sarcoma Res 2018;8:8.

35. Saltus CW, Calingaert B, Candrilli S, Lorenzo M, D’Yachkova Y, Otto T, et al. Epidemiology of adult soft-tissue sarcomas in Germany. Sarcoma 2018;2018: 5671926.

36. Bessen T, Caughey GE, Shakib S, Potter JA, Reid J, Farshid G, et al. A populationbased study of soft tissue sarcoma incidence and survival in Australia: an analysis of 26,970 cases. Cancer Epidemiol 2019;63:101590.

37. Agaram NP, Zhang L, LeLoarer F, Silk T, Sung YS, Scott SN, et al. Targeted exome sequencing profiles genetic alterations in leiomyosarcoma. Genes Chromosomes Cancer 2016;55:124-30

38. Chudasama P, Mughal SS, Sanders MA, Hubschmann D, Chung I, Deeg KI, et al. Integrative genomic and transcriptomic analysis of leiomyosarcoma. Nat Commun 2018;9:144.

39. Shapiro GI, O'Mara E, Laskin OL, Gao L, Baird JD, Spiegel RJ, et al. Pharmacokinetics and safety of PTC596, a novel tubulin-binding agent, in subjects with advanced solid tumors. Clin Pharmacol Drug Dev 2021.

40. Ravelli RBG, Gigant B, Curmi PA, Jourdain I, Lachkar S, Sobel A, et al. Insight into tubulin regulation from a complex with colchicine and a stathmin-like domain. Nature 2004;428:198-202.

41. Hoffman LM, Veldhuijzen van Zanten SEM, Colditz N, Baugh J, Chaney B, Hoffmann M, et al. Clinical, radiologic, pathologic, and molecular characteristics of long-term survivors of diffuse intrinsic pontine glioma (DIPG): a collaborative report from the International and European Society for Pediatric Oncology DIPG Registries. J Clin Oncol 2018;36:1963-72.

42. Cao L, Weetall M, Trotta C, Cintron K, Ma J, Kim MJ, et al. Targeting of hematologic malignancies with PTC299, a novel potent inhibitor of dihydroorotate dehydrogenase with favorable pharmaceutical properties. Mol Cancer Ther 2019;18:3-16. 